remove all the starch, and indeed that the granules then tended to clump together. However, a detergent solution gives better results. Another approach is to find a safer powder: recently sodium bicarbonate has been suggested.

The dusting powder is not only used to help the surgeon in putting on his gloves but is also necessary in the manufacturing process. Surgical gloves are made by dipping hand-shaped moulds into latex, and release agents are placed on the surface of the mould before the dipping process to facilitate subsequent removal of the glove. In 1975 a disconcerting report by Henderson and his colleagues ${ }^{7}$ from Cardiff showed that surgeons' gloves studied by electron microscope microanalysis showed the presence of talc as well as large amounts of zinc and sulphur. These particles of talc were present on the outer surface of the gloves and were extremely small, some $20 \mathrm{~nm}$ in diameter. Apparently talc was still used in the manufacturing process and the filter systems were failing to prevent access of these fine talc crystals. The same authors studied sections from six examples of starch granulomas, and here, too, they showed quantities of talc particles as well as the starch. Recently, Tolbert and Brown ${ }^{8}$ have confirmed the presence of talc on the outside surfaces of the surgical gloves produced by six out of the eight major American manufacturers. Some of these particles remained on the surfaces of the glove even after careful lavage in isotonic saline solution and wiping the gloved hands with fresh lint-free cloths.

The risks of granuloma formation after the use of glove dusting powder are small, but they have not been eliminated: the search for the ideal lubricant has clearly not ended.

1 Fulton JF. Harvey Cushing. Oxford: Blackwell Scientific, 1946.

2 Lee CM, Lehman EP. Experiments with nonirritating glove powder. Surg Gynecol Obstet 1947;84:689-95.

${ }^{3}$ Cade $\mathrm{D}$, Ellis $\mathrm{H}$. The peritoneal reaction to starch and its modification by prednisone. Eur Surg Res 1976 ;8:471-9.

${ }^{4}$ Jagelman DG, Ellis H. Starch intraperitoneal-adhesion formation. $\mathrm{Br} \mathcal{F}$ Surg 1973;60:111-4

${ }^{5}$ Anonymous. Glove powder : a surgical hazard. $B r$ Med f 1973;ii:502-3.

6 Warshaw AL. Diagnosis of starch peritonitis by paracentesis. Lancet 1972 ;ii:1054-6.

7 Henderson WJ, Melville-Jones C, Barr WT, Griffiths K. Identification of talc on surgeons' gloves and in tissue from starch granulomas. $\mathrm{Br} \mathcal{F}$ Surg 1975;62:941-4.

8 Tolbert TW, Brown JL. Surface powders on surgical gloves. Arch Surg $1980 ; 115: 729-32$.

\section{Management of Crohn's disease: Time for audit?}

\begin{abstract}
"Medical treatment is purely palliative and supportive," wrote Crohn almost 50 years ago, discussing the management of the disease that bears his name. ${ }^{1}$ At that time he believed that surgery was the treatment of choice for regional ileitis, but a sceptic might think his words not so wide of the mark in 1980. The introduction of steroid treatment during the 1950s promised easy control of the disease. Nevertheless, subsequently retrospective studies showed that steroid drugs often gave only short-term benefits and might even be harmful. ${ }^{2-4}$ Controlled prospective trials then became the order of the day. Sadly, after more than 10 years' work and a mountain of contradictory data on steroids, sulphasalazine, and immunosuppressive agents we are still unable to recommend any particular regimen. ${ }^{5}$
\end{abstract}

Scientific decision making is particularly difficult in Crohn's disease because of the multiplicity of sites affected and the protean clinical manifestations. Investigations of even large series of patients tend to finish up as analyses of many small subgroups. Clinical decision making may be made easier by using the patient as his own control, and hence regular followup is important because it helps the doctor to get to know his patient, besides performing clinical and laboratory assessments. Regular observation may create its own problems, such as the patient with few symptoms but laboratory evidence of inflammation. Should the doctor then treat the patient or the abnormal blood test results? In Britain most physicians use the minimum treatment to keep the patient comfortable and at work. Korelitz ${ }^{6}$ has recently criticised this policy of passive observation, however, advocating early suppression of indicators of disease activity. There is no evidence from controlled studies to support either view.

In the United States a national study was set up to determine which therapeutic agents would suppress the acute disease and maintain remission over two 17 -week periods. ${ }^{7}$ Not only have the design and interpretation of the trial been criticised but the response was monitored by a disease activity index which was so complicated that it was best derived by a programmable calculator. ${ }^{8}$ Active disease was most effectively suppressed by steroids, but sulphasalazine was also better than placebo; a combination of the two drugs conferred no added advantage. Azathioprine was ineffective. No drug was better than placebo in maintaining remission and all three regimens produced side effects.

Except in some centres, ${ }^{9}$ the use of azathioprine has never been wholeheartedly endorsed because of the fear of side effec's; for instance, Willoughby ${ }^{10}$ recommended that treatment should be limited to a one-year course to prevent the possible development of malignancy. Such restrictions cause further problems, because most patients become drug dependent and relapse on withdrawal. A report of a recent double-blind cross-over trial has renewed interest in immunosuppressive treatment in the United States. ${ }^{11}$ Treatment with 6-mercaptopurine reduced the need for steroids, closed fistulae, and ameliorated signs and symptoms. The response was often slow and might be delayed for up to four months after onset of treatment. Side effects occurred in $10 \%$ of patients but were reversible. The dosage had to be monitored by the haematology laboratory in much the same way as anticoagulant treatment-a requirement that should at least discourage indiscriminate use of the drug.

In the light of these recent studies and reviews, how should the busy clinician attempt to manage his outpatients with Crohn's disease? Probably the best approach is to measure a simple index of disease activity ${ }^{12}$ and use the least harmful regimen that will control symptoms. Drugs to suppress diarrhoea and relieve bowel spasm and pain may be used with caution. A diet containing unrefined carbohydrate with extra fibre as raw fruit and vegetables may prevent relapse without inducing intestinal obstruction ${ }^{13}$; the role of added bran has not been determined. Anaemia and other nutritional deficits should be corrected. Though the documented evidence is sparse, sulphasalazine seems worth prescribing for both acute symptoms and prophylaxis. Steroids should be given if the symptoms do not come under control, and if the patient needs hospital admission corticotrophin may be the drug of choice. An attempt should be made to wean the patient off steroids after a few months, but many become drug dependent and will relapse. Further attempts at slow reduction of steroid dosage should be made thereafter. Surgery should be considered and reconsidered at all stages of the disease, but we have no satisfactory data to tell us when and how to operate. ${ }^{5}$ Immuno- 
suppressives are perhaps best reserved for patients who need their steroid dose reduced or who cannot tolerate sulphasalazine or surgery and need maintenance treatment. The results of the few really long-term follow-up studies of patients with disease of the distal ileum ${ }^{14}$ or colon ${ }^{15}$ suggest that most such patients have a good prognosis and manage without long-term steroids; but most do also come to operation, with good results and no rise in the cumulative recurrence rate. The aim should therefore always be the withdrawal of steroid and other specific treatment, with the judicious use of surgery and limited courses of specific drugs for acute exacerbations.

1 Crohn BB, Ginzburg L, Oppenheimer G. Regional ileitis. $\mathcal{f} A M A 1932$ 99:1323-9.

2 Jones JH, Lennard-Jones JE. Corticosteroids and corticotrophin in the treatment of Crohn's disease. Gut 1966;7:181-7.

${ }^{3}$ Roberts GM, Naish JM. Corticosteroids in Crohn's disease. Gut 1968;9: 736.

${ }^{4}$ Cooke WT, Fielding JF. Corticosteroid or corticotrophin therapy in Crohn's disease (regional enteritis). Gut 1970;11:921-7.

5 Riis P. A critical survey of controlled studies in the treatment of ulcerative colitis and Crohn's disease. Clin Gastroenterol 1980;9:351-69.

${ }^{6}$ Korelitz BI. Therapy of inflammatory bowel disease, including use of immunosuppressive agents. Clin Gastroenterol 1980;9:331-49.

7 The National Cooperative Crohn's Disease Study. Gastroenterology 1979; $77: 825-944$.

${ }^{8}$ Best WR, Becktel JM, Singleton JW. Rederived values of the eight coefficients of the Crohn's disease activity index (CDAI). Gastroenterology $1979 ; 77: 843-6$.

${ }^{9}$ O'Donoghue DP, Dawson AM, Powell-Tuck J, Bown RL, LennardJones JE. Double-blind withdrawal trial of azathioprine as maintenance treatment for Crohn's disease. Lancet 1978;ii:955-7.

10 Willoughby JMT. The management of Crohn's disease. Hospital Update 1976;2:647-56.

${ }^{11}$ Present DH, Korelitz BI, Wisch N, Glass JL, Sachar DB, Pasternack BS. Treatment of Crohn's disease with 6-mercaptopurine. A long-term, randomized, double-blind study. $N$ Engl f Med 1980;302:981-7.

12 Harvey RF, Bradshaw JM. A simple index of Crohn's-disease activity. Lancet $1980 ; \mathrm{i}: 514$.

${ }^{13}$ Heaton KW, Thornton JR, Emmett PM. Treatment of Crohn's disease with an unrefined-carbohydrate, fibre-rich diet. Br Med f 1979;ii :764-6.

${ }^{14}$ Higgins C, Allan RN. Crohn's disease of the distal ileum. Gut (in press)

15 Allan R, Steinberg DM, Williams JA, Cooke WT. Crohn's disease involving the colon: an audit of clinical management. Gastroenterology $1977 ; 73: 723-32$.

\section{The dangers of thinness}

The average weight of the inhabitants of Framingham, Massachusetts, aged 30-59 years is rather greater than the Metropolitan Life Insurance Company's "ideal weight" for height. ${ }^{1}$ The same is true of other large population samples in the United States ${ }^{2}$ and in Britain. ${ }^{3}$ Since the insurance companies' ideal weight is the weight associated with minimum mortality, we might expect that moderately overweight average men and women would have a higher death rate than relatively slim people of "ideal weight," but a recent publication from Framingham says that this is not so. ${ }^{4}$

The insurance companies based their ideal weight for height on the death rates in a large series of people issued with policies from 1935 to $1953^{5}$; their clients were weighed and measured clothed and wearing shoes. In comparisons with series in which the subjects were weighed partially clothed and measured without shoes, height has to be adjusted by $2.5 \mathrm{~cm}$ for men and $5 \cdot 1 \mathrm{~cm}$ for women, and weight by $3 \mathrm{~kg}$ for men and $2 \mathrm{~kg}$ for women. When these corrections are made the desirable range of weights is conveniently expressed as the ratio $\mathrm{W} / \mathrm{H}^{2}$, where $\mathrm{W}$ is weight in $\mathrm{kg}$ and $\mathrm{H}$ is height in $\mathrm{m}$; the desirable range for men is 20-25 and for women 19-24. ${ }^{6}$

The new analysis from the Framingham study 4 concerns men and women aged 40-69 years, observed over six-year periods. The grouping of weight and height is that used in the build and blood pressure study of the "insurance" series; there is no lower limit to the weights included, but there is an upper limit of $116 \mathrm{~kg}$. The body-build groups (converted into $\mathrm{W} / \mathrm{H}^{2}$ notation) are: less than 21, 21-26, 26-29, 29-32, and over 32 . Since the Framingham study has now been running for 24 years the total cohort of 5209 men and women could be reclassified by age and weight three times, to provide four consecutive six-year follow-up periods. During this period 717 men and 578 women died.

When observed is compared with expected mortality in each group, the small number in the thinnest group (about 3\% of men and $6 \%$ of women) are seen to have fared worse than average. This could be partly, but not completely, explained by the excess of smokers in the thinnest group. The cause of the excess mortality among thin people is not clear. In the American Cancer Society study ${ }^{2}$ of about 750000 men and women, there was an upturn in mortality at $\mathrm{W} / \mathrm{H}^{2}$ values less than 21 for men and less than 18 for women; in both sexes this was attributable to an increased death rate from digestive diseases and cerebrovascular disease, and in men from cancer. In the Framingham series in men the excess risk for those more than $20 \%$ below average weight is similar to the risk for those who were $20-29 \%$ above average weight; but to be 30 $39 \%$ above average weight carries double the risk, and over $40 \%$ above average treble the risk. Women have a less striking increase in death rate associated with underweight, but deviations above average weight carry an excess risk similar to that seen in men.

What, then, is ideal weight ? Long-term studies in men $^{7}$ and women ${ }^{8}$ show that thinner people live longer. In these studies, however, weight is defined by weight at entry, whereas in the recent Framingham analysis ${ }^{4}$ weight was redefined every six years. People change in weight with time, though the average weight of groups of people remains remarkably constant. ${ }^{9}$ In the first 18 years of the Framingham study the difference between maximum and minimum weight for the average man or woman was $10 \mathrm{~kg}$, ${ }^{1}$ which is enough to cross an entire bodybuild group. The message seems to be that if you are in the $\mathrm{W} / \mathrm{H}^{2}$ group $20-25$ and are planning to leave it you will probably be slightly safer crossing the upper boundary than the lower one.

1 Gordon T, Kannel WB. The effects of overweight on cardiovascular diseases. Geriatrics $1973 ; 28$, No $7: 80-8$.

2 Lew EA, Garfinkel L. Variations in mortality by weight among 750,000 men and women. $\mathcal{F}$ Chronic Dis 1979;32:563-76.

${ }^{3}$ James WPT, ed. Research on obesity: a report of the DHSS/MRC group. London: HMSO, 1976.

${ }^{4}$ Sorlie P, Gordon T, Kannel WB. Body build and mortality: the Framingham study. FAMA $1980 ; 243: 1828-31$.

5 Seltzer CC. Some re-evaluations of the build and blood pressure study 1959 as related to ponderal index, somatotype and mortality. $N \mathrm{Englf}$ Med $1966 ; 274: 254-9$.

6 Garrow JS. Weight penalties. Br Med F 1979;ii:1171-2.

${ }^{7}$ Blair BF, Haines LW. Mortality experience according to build at the higher durations. Transactions of the Actuarial Society of America 1966;18:35-41.

${ }^{8}$ Cochrane AL, Moore F, Baker IA, Haley TJL. Mortality in two random samples of women aged 55-64 followed up for 20 years. Br Med $\mathcal{F} 1980$; 280:1131-3.

${ }^{9}$ Garrow JS. Energy balance and obesity in man. Amsterdam: Elsevier/North Holland, 1978. 